\title{
LIBERDADE, CRIAÇÃO E FINITUDE EM SARTRE: DA QUALIDADE SINGULAR À GENEROSIDADE
}

\author{
Marcelo Prates ${ }^{1}$ \\ Universidade Estadual do Centro-Oeste (UNICENTRO) \\ (i) https://orcid.org/0000-0001-5180-6053 \\ E-mail: marceloprates1@gmail.com
}

\section{RESUMO:}

O objetivo deste artigo é apresentar a noção de criação no pensamento de Sartre. Tal noção não é predominante nos primeiros textos. Procuramos demostrar seu lugar no pensamento do filósofo. Primeiramente recorremos ao texto dos Cahiers pour une morale onde tal noção ocupa um lugar fundamental. Em seguida, mostramos como tal análise é retomada sobretudo na Critique de la Raison Dialectique. Tal análise explicitará o teor da criação como processo de singularização, de modo que o ser do indivíduo ou sua liberdade seja tomada enquanto uma qualidade singular, ou ainda, como sentido do ser enquanto finitude. Por fim, que essa configuração alude às relações segundo sua doação e generosidade enquanto existência no mundo.

PALAVRAS-CHAVE: Dialética; Sartre; Liberdade; Finitude.

\section{FREEDOM, CREATION AND FINITUDE IN SARTRE: FROM SINGULAR QUALITY TO GENEROSITY}

\begin{abstract}
:
This article aims to analyze the notion of creation in Sartre's thought. This notion is not predominant in the first texts. We try to demonstrate their place in the philosopher's thinking. First, we turn to the text Cahiers pour une morale where such a notion occupies a fundamental place. Then, we show how this analysis is resumed in the Critique of Raison Dialectique. This analysis will explain the content of creation as a process of singularization so that the being of the individual or his freedom is taken as a singular quality, this is, as meaning of being while it is finitude. Finally, this configuration alludes to relations according to his gift and generosity as existence in the world.
\end{abstract}

KEYWORDS: Dialectic; Sartre; Freedom; Finitude.

\footnotetext{
${ }^{1}$ Doutor em Filosofia pela Universidade Federal do Paraná (UFPR), Curitiba - PR, Brasil. Professor colaborador na Universidade Estadual do Centro-Oeste (UNICENTRO), Guarapuava - PR, Brasil.
}

PRATES, Marcelo. Liberdade, criação e finitude em Sartre: da qualidade singular à generosidade. Griot : Revista de Filosofia, Amargosa - BA, v.19, n.2, p.1-21, junho, 2019. 
A noção de criação aparece sempre de maneira lateral nos principais escritos filosóficos de Sartre, sobretudo por duas razões. A primeira é a própria ideia de fenômeno tomado da fenomenologia que tem como natureza a intencionalidade. Ora, uma vez que não há distinção entre sujeito e objeto, mas eles são polos de um mesmo fenômeno, o fenômeno aparece como absoluto: "o ser do existente é exatamente o que o existente aparenta [...] porque ele é absolutamente indicativo de si mesmo" (SARTRE, 2007, p. 12). Portanto, não haveria na dimensão fenomenológica uma criação de fenômeno. A segunda seria na dimensão ontológica. A partir da crítica à ideia de fenômeno em Husserl, de que a série infinita de noemas faz com que o fenômeno perca sua objetividade, Sartre postula um ser do fenômeno como sua dimensão transfenomenal, ser esse que é incriado, pois aparece como absoluto, e que também não cria, pois é apenas uma das condições do fenômeno. Sartre apelará à consciência enquanto outra dimensão transfenomenal do fenômeno, cujo sentido ontológico ou para-si denota sua natureza como nada de ser.

A partir dessa dinâmica da dupla dimensão transfenomenal do fenômeno, este é pensado como uma tensão entre ser e nada, cujo sentido geral, ou Ser, é a ideia da totalidade faltada ou o impossível em-si-para-si. Por isso, essa duplicidade transfenomenal não criaria fenômenos, embora seja condição para a aparição. Condição, posto que a aparição é uma tentativa de relação impossível e, uma vez impossibilitada a relação efetiva, o fenômeno é tomado em sua natureza como aparência, nada de ser. Assim, o fenômeno seria apenas o modo como o ser se desvela para si a partir da facticidade, da contingência de ser que lhe cabe em seu horizonte. Daí que o ser da consciência, ser emprestado como dirá Sartre, seja nada, poder nadificador cuja determinação é negativa na medida em que aparece como não sendo o ser. É por isso que Sartre prefere ali nos escritos fenomenológicos a noção de causa sui (Idem, p. 20) à noção de criação, uma vez rejeitada a tese da analogia do ser, pois o fenômeno não aparece como o criado análogo ao ser, nem como seu efeito, posto que a causa sui enquanto impossível em-si-para-si implica a impossibilidade do efeito e da criação Deste modo, o Ser não cria e nem causa, posto que o fenômeno aparece como resultado dessa impossibilidade, enquanto nada de ser.

Assim, o fenômeno é condicionado por uma dupla transfenomenonalidade, cujo sentido geral denota uma tensão entre ser e nada no bojo mesmo do Ser, e que tem o fenômeno como resultado dessa tensão. Isso se traduz na impossibilidade do fundamento e, portanto, da Metafísica. Com isso se fecha a possibilidade de uma análise genética do fenômeno e restituímos o mesmo à contingência absoluta do ser. Ademais, esse ser é incriado e se encontra empastado de si mesmo, sem relação alguma fora dele. Tal é o sentido da contingência: "um existente fenomênico, enquanto existente, não pode jamais ser derivado de um outro existente. É o que chamamos a contingência do ser-em-si [...] incriado, sem razão de ser, sem relação alguma com outro ser, o ser-em-si é demais (de trop) para a eternidade" (Idem, p. 33) Por isso a liberdade parece figurar, pela nadificação da consciência, uma angústia constante que denota o caráter de um presente perpétuo, de um vazio ou desespero, e que aponta sempre ao fracasso irrealizante da consciência que não escapa à aporia do ser e do nada. Nesse sentido, a liberdade aparece como uma desvelação do ser, mas nunca uma criação, pois na estrutura ontológica não há guinada do fundamento,

PRATES, Marcelo. Liberdade, criação e finitude em Sartre: da qualidade singular à generosidade. Griot : Revista de Filosofia, Amargosa - BA, v.19, n.2, p.1-21, junho, 2019. 
enfim, não há realização do ser ou no ser. Daí o sentimento de absoluta leveza que a liberdade pode denotar: estamos aí, mas para nada.

Essa é a maneira mais geral de visualizar os postulados da fenomenologia de Sartre e o sentido que a criação poderia ter nessa primeira parte da sua filosofia passa por aí. $O$ interessante é que à medida que ela vai se transformando, isto é, sobretudo pela passagem à dialética e à assunção da finitude do finito, ou seja, quando passa a se tomar a liberdade na sua criação de si e não apenas na tentativa de se fundamentar, esta dimensão conquista maior relevância. $O$ objetivo de nosso texto é apresentar essa guinada da noção de criação nos textos de Sartre e qual a consequência maior a partir desta nova ênfase. Num primeiro momento resgatamos a ideia de criação e a partir dela a consolidação do humanismo existencial proposto por Sartre, o qual possibilita a tomada da liberdade como criação de si e da História. Em seguida, mostramos que tal criação apela à finitude em sua condição, de modo que denota o indivíduo segundo sua coloração própria enquanto singularidade, cujo empreendimento arrasta e transforma toda a cultura. Por fim, que essa configuração alude às relações segundo sua doação e generosidade enquanto existência no mundo.

Já nos Cahiers, escrito póstumo, encontramos essa mudança de ênfase, embora ele ainda esteja sob o signo do fundamento ou em-si-para-si. Como aponta Frajoliet (2005, p. 9), a criação é um conceito onipresente na moral ontológica de 4748. Ela passa a ser associada à ação que tomava a cena central na liberdade em $O$ ser e o nada. Doravante, a ação é denotada também como criação: "criação do mundo, de mim mesmo e do homem" (SARTRE, 1983, p. 129). Por isso, a criação assume, em alguns momentos da obra, a figura central, passando desde o seu estatuto ontológico até a relação com o outro.

Ainda que associe a criação à ação, o fundo geral da análise ali elaborada pensa a criação em termos ontológicos, onde a contingência aparece como a "motivação profunda de todas as criações" (Idem, p. 536). Isso porque Sartre retoma, em parte, as análises iniciais de $O$ ser e o nada onde pensa o estatuto do fenômeno e do ser. Como apontamos no início, o ser é posto como incriado. No entanto, é mudada a percepção sobre o ser como incriado enquanto contingente. Isso porque ainda que o ser seja empastado de si mesmo e sem relação, o ser incriado não é eterno, mas, antes, criação de si: "O ser criado depende do incriado. Mas o incriado não pode ser pura existência eternamente dada. Ele só pode ser sua própria criação. Assim, o mito da criação divina tem esse primeiro sentido: A criação só poder vir ao ser por um ser que é a si mesmo sua própria criação" (Idem, p. 530, negrito meu). Com isso, Sartre volta a associar a tese da imanência do em-si com a transcendência do para-si, pois, e este é o segundo sentido da ideia de criação, só se pode ser sua própria criação "no e pelo projeto de criar fora dele o ser." (Ibid.). O importante é perceber como isso entrega à realidade humana a total condição de sua criação mesmo na contingência. Nesse caso, a motivação é tanto ontológica quanto ôntica, uma vez que apela ao mesmo tempo à negatividade e à intencionalidade, pois "criação significa começo primeiro e produção intencional" (Idem, p. 134), e quanto ao ser externo criado, este só pode ser o próprio mundo. Assim, ação, criação de si e criação do mundo é uma e mesma coisa. Por isso Sartre não fará distinção entre a causa sui e a causa mundi (Idem, p. 533) 
Com relação ao para-si, ele é projeto de ser. E aparece como uma maneira de se apropriar do em-si, de modo que toda construção e modificação ôntica aparece sobre esse signo (Idem, p. 134). Isso porque ele não pode criar segundo a forma do sujeito e objeto que alude a uma irredutibilidade entre os elementos, pois isso seria criar uma distância infinita entre eles de modo a definir uma absoluta incomensurabilidade: "Na verdade, a ligação do criador com a criatura é de dependência recíproca: é criando a coisa que o criador existe" (Ibid.), de modo que "é na própria coisa criada que ele se cria, e não na indistinção de uma subjetividade. $O$ criador deve ser puro ultrapassamento da facticidade rumo à criação de si mesmo no mundo da facticidade" (Ibid.). Por isso, a criação do mundo não é distinta da criação de si, mas aparecem apenas em momentos diferentes da análise, seja a dimensão de transcendência, resguardada no para-si enquanto negatividade e a criação como derivada desta (Idem, p. 156), seja pelo em-si, que adentra e se configura na vida humana como situação histórica e material. "Originalmente, portanto, só se pode criar a si mesmo. Mas se criamos na dimensão do em-si que não somos. A criação é um ato de um para-si que se produz face a si como em-si." (Idem, p. 158). Por isso a noção de causa sui associa a causa à subjetividade e o sui como objeto externo (Idem, p. 132), mas que denota, na unidade sintética deste ato, a existência como "no meio do mundo, isto é, como elemento de um sistema finito que lhe confere sua forma (Ibid.). Com isso Sartre rejeita qualquer alteração no mundo pelo próprio ser, ou ainda por um Espirito ou Natureza com leis misteriosas. Toda mudança é um projeto, uma negação do estado atual rumo ao que ainda não é no mundo. Como a nadificação é sempre sob um fundo de ser, essa relação sintética supõe a nadificação como condição transformadora do mundo na medida mesma em que exige dessa nadificação uma forma, uma maneira, enfim, um projeto de ser. Portanto, e é isso que procuramos enfatizar, no seio da contingência do ser incriado, a criação do mundo implica a criação de si mesmo: "Na verdade, a escolha é escolha de criar para além do mundo um estado que não é ainda, que não é uma projeção, e que é ao mesmo tempo eu mesmo" (Idem, p. 134, 135)

Ora, sendo uma forma de fundamentação frustrada, tensão entre ser e nada, Sartre ainda vê a criação como busca do em-si-para-si e, portanto, é para a reflexão cúmplice que ela se desvelaria como criação (Idem, p. 156). Queremos "fundar tudo" (Ibid.), de modo que a criação aparece também sob esse signo. Todavia, esse movimento não é separado do processo de existência do para-si. Por isso que esse movimento aparece de modo mais imediato na dimensão ego, pois é justamente nele que o homem se concentra ao criar, na medida em que imprime seu eu nas coisas e no mundo para poder dizer que os produziu. Mas Sartre pensa que a criação tomada nesse sentido dimensiona a uma perda na sua característica de novidade (Idem, p. 536), porque o ego aparece como uma reificação estática e não como subsumido à personalização e o projeto existencial como liberdade: "Criando, o homem se cria. Mas isso não significa que ele imprime na dimensão do Em-si um Eu já existente; muito ao contrário, é do que ele cria que ele apreende o que é" (Idem, p. 543). Por isso, embora fadado à alienação primordial do em-si, sendo criação de si mesmo por sua própria existência, não é ela que atrofia ou dissimula esse movimento de criação que é a própria existência, mas os signos transcendentes, os quais solidificam o movimento, como o caso do Ego. Por isso a reflexão pura, que deveria ser uma forma 
de purificação da reflexão cúmplice, esta onde se toma a transcendência a partir do transcendente, teria por função, ao devolver o para-si a sua própria condição de fluxo nadificador e historicidade fáctica, liberar essa dimensão de criação dos atolamentos que a sucumbem.

Por isso a tarefa da reflexão pura, ou da atitude crítica na Crítica, seria "desvelar a criação sob as atividades de apropriação e identificação" (Idem, p. 530), restituindo à ação humana a sua compreensão como criadora. Deste modo, enquanto é também o resultado da reflexão pura, a criação superaria tanto a vida moral, comandada pelo espírito de seriedade (Idem, p. 526), quanto a vida do trabalho, pois uma vez que o homem se move no mundo como aquilo que a princípio é o já criado (Idem, p. 530) a ação, seja moral, seja produtiva, tende a guiar-se pela repetição do já existente e, nesse caso, produzir ou agir se torna apenas uma maneira de reproduzir. Embora Sartre reconheça que é quase impossível não ter esse traço em nossa existência, isto é, alguma dimensão do nós enquanto ação conjunta, homogênea, massificada e repetitiva, não é essa a dimensão que é o motor da ação e transformação, mas a ação individual. Por isso, essas dimensões alienantes que paralisam a consciência são sempre transcendentes e secundárias, como, por exemplo, o mundo do trabalho que faz do trabalhador um sujeito, para usar as expressões do Cahiers, inecessencial, isto é, uma função sem sujeito cuja finalidade é a reprodução indefinida. Assim, "a realidade do trabalho implica a irrealidade do trabalhador; a realidade da produção implica a não-realidade do produtor" (Idem, p. 525). Ele se apreende apenas como um contribuinte que mantém a forma dinâmica já existente e cuja produção passa a ser mecânica (Ibid.), tal qual o modo de vida serial, e uma vez que "o trabalhador não reencontra jamais sua parte de criação sob o objeto produzido" (Ibid.) sua ação como resultado da sua vida e produção da mesma só pode cair na massificação, na des-individuação pelo mundo. Nesse caso, ele anula a individualidade própria se coagulando no trabalho conjunto. Ainda que Sartre veja que há ali uma singularidade histórica, e que determinados empreendimentos possam exigir tal dimensão, esta, em geral, sucumbe à vida serial. Daí que Sartre acabe reservando essa possibilidade de criação mais efetiva, ou mesmo de vida criativa, à apenas algumas atividades como a engenharia e a arte (Idem, p. 552), sobretudo essa última que teria como propósito "apresentar o mundo como nós vemos como produto de uma liberdade" (Idem, p. 568), sendo as demais, em geral, assentadas na dimensão serial ou, para usar uma expressão da Crítica da razão dialética, no práticoinerte.

Deste modo, e é o que procuramos enfatizar, nos Cahiers Sartre apresenta uma intensa (e também longa, pois perpassa vários pontos que não teriam espaço para se discutir aqui) relação entre a liberdade e a criação. $O$ que procuramos ressaltar é a recuperação dessa dimensão já em um escrito posterior a $O$ ser e o nada, embora publicado apenas postumamente (e com isso a discussão pode apresentar-se ausente da obra publicada, mas não do seu pensamento). Mas isso já é o bastante para mostrar também a preocupação com a produção do novo e a relação necessária entre criação de si e criação do mundo. Por isso, e para enfatizar, assegurará Sartre que "é impossível separar a Causa sui da Causa mundi, dando a elas a "mesma natureza" (Idem, p. 160). Ora, na finitude do mundo essa relação da transcendência interna ao ser que o faz causa sui, qualifica (Idem, p. 161) essa nadificação (a infesta 
de ser, mas na singularidade do ato) e faz com que a criação seja e não seja ao mesmo tempo, enfim, que ela se apresente não como o ser absoluto, ou um movimento que totaliza até o limite do Ser, mas se expresse como uma maneira de ser (Ibid.), criada na e pela finitude do agente. Em outras palavras, toda existência é criação finita no fenômeno, mas não desenvolvimento do Ser ou do Espírito ou Natureza. Por isso que uma fenomenologia da liberdade deveria tomar como fenômeno não o Ser, mas as liberdades concretas enquanto ser-finito. É só assumindo a finitude como condição própria do Ser que a ideia de criação pode figurar ao mesmo tempo a liberdade, o fenômeno, e o Ser em sua contingência, enquanto relação entre o ser e o nada. Só aqui, também, a ontologia assume o fenômeno na sua dimensão absoluta sem perder a sua natureza criadora, pois enquanto finitude, a impossibilidade do fundamento se traduz enquanto radicalização do meu ser, fazendo da realidade humana o apanágio do ser e do fundamento. Em outras palavras, é só sendo sem fundamento que o homem pode criar a si mesmo, mas somente a si mesmo (na dimensão do mundo, mas não na realização ou guinada do fundamento). É o fenômeno enquanto liberdade posto como fundamento por sua própria finitude. Deste modo, "o Para-si só pode ser seu próprio fundamento no projeto de criar o mundo e só pode conceber de criar o Mundo para fundar a si mesmo na dimensão do ser-em-si" (Idem, p. 142). Isso alude que o homem não é um ser nem um nada, mas um medium entre ser e nada (diríamos, para lembrar Roquentin, que não é a pura angústia, esse nada que surge no coração do ser, nem o ser empastado, mas essa náusea no estômago, desalento interno do mundo na medida em que sou a própria náusea). É, por isso, a causa de si e, sendo contingente, se cria a si mesmo "indiretamente, isto é, pela intermediação infinita do mundo" (Idem, p. 134). Portanto, a escolha original não é nenhum talento ou alguma realidade encontrada "em certas circunstâncias', mas operação" (Ibid.), transformação de si no mundo e com o mundo. Qualquer vida irrompida é não só uma novidade irredutível como a única condição de criação no mundo.

O importante dessa análise é que ela corrobora a guinada dialética no pensamento de Sartre bem como assenta, na dialética, a dinâmica criadora da liberdade. Isso é expresso sobretudo porque só pela liberdade o novo aparece na realidade. Por isso que a criação não se dirige a nenhuma espécie de talento, mas à escolha original (Ibid.) daquela condição cujo resultado objetivado não é apenas recuperação subjetiva, mas se apresenta como novo e faz do próprio mundo uma novidade constante na História. Nesse caso, a realidade do novo não depende apenas da subjetividade do agente, mas de todo o meio circundante, seja material, seja da alteridade. É só assim que essa novidade, embora irrompida da contingência, também possuirá profundidade histórica. Com isso, essa novidade que não pode ser distinta do projeto que a engendra, é ontologicamente o aparecimento de um novo sentido do ser pela maneira de ser dessa subjetividade que a engendra, como também uma significação nova no campo prático (Idem, p. 543, 549). Assim, sendo projeto, seja pela objetividade da exteriorização e encontro com o outro, seja pela subjetividade e projeto fundamentado pela nadificação, ambos os movimentos apontam à vivência em seu projeto de ser. É em todo transcorrer da vida do indivíduo que ele se cria e cria o mundo. Portanto, o novo não é um ato ou um objeto, mas um processo vivido historicamente. Por isso, essa novidade não é distinta do processo de personalização (posto que é criação de si), uma vez que

PRATES, Marcelo. Liberdade, criação e finitude em Sartre: da qualidade singular à generosidade. Griot : Revista de Filosofia, Amargosa - BA, v.19, n.2, p.1-21, junho, 2019. 
aparece na maneira subjetiva como singularidade e qualidade de ser por ser uma novidade irredutível:

O novo, na medida em que é novo, parece escapar ao intelecto: aceita-se a
qualidade nova como uma aparição bruta ou, melhor ainda, supõe-se que
sua irredutibilidade é provisória e que, mais tarde, a análise há de
descobrir nela elementos antigos. Mas, precisamente o novo vem ao mundo
pelo homem: é sua práxis (no próprio nível da percepção: cores, odores)
que, pela reorganização parcial ou total do campo prático, produz a nova
ferramenta na unidade nova de sua aparência e de sua função (SARTRE,
2002a, p. 175).

Observe-se que enquanto a criação não era associada a ação, a liberdade aparecia mais na sua angústia e diferença do ser que na relação de criação enquanto fenômeno. Há, como vimos, essa reparação no Cahiers, mas é na Crítica da razão dialética que se consolida de maneira mais veemente essa lógica de investigação do novo: "se a Razão dialética existe, é necessário que ela se defina como a inteligibilidade absoluta de uma novidade irredutível na medida em que esta é uma irredutível novidade" (Idem, p. 174 e 175). Por isso a tarefa de crítica do presente em Sartre, a de buscar as condições de liberdade hoje, supõe a inteligibilidade das novidades irredutíveis pela própria práxis e existência do homem, pois "o pensamento humano (enquanto é, em si mesmo, práxis e momento da práxis) caracteriza-se fundamentalmente como a inteligência do novo" (Idem, p. 178):

O novo é o vestígio deixado por uma temporalização totalizante sobre a absoluta dispersão inerte que representa o espaço. É inteligível na medida em que a inércia dispersiva que ela consegue reunir nada acrescenta por si mesma e não passa da reprodução cristalizada do ato gerador (Idem, p. 179 , nota 16).

E se o mundo é o resultado de uma tensão que alude sobretudo a uma ausência de fundamento cujo sentido é a exterioridade de indiferença, ou contingência, Sartre faz da própria irrupção desse novo a condição para que o mundo não desvaneça na exterioridade de indiferença, isto é, "é preciso que o mundo inteiro seja fundado" (SARTRE, 1983, p. 550). Se Sartre associa mundo ao humano no sentido de dizer que só há mundo humano, é pela categoria do novo que fará tal associação (BORNHEIM, 1983, p. 229). É a criação, na sua finitude, que totaliza o mundo enquanto criação de si mesma. Do contrário, seria impossível supor que a criação fosse um ato de liberdade total. É porque o novo vem ao homem pelo homem que o mundo pertence a ele e ele é criador do mundo, a despeito do ser contingente. Mas isso revela também que esta novidade é assentida pela existência do outro à medida que este outro implica uma negatividade como não sendo como os demais, o que aponta a condição de multiplicidade dessa criação do mundo (e que permite escapar ao idealismo), uma multiplicidade que exige um pululamento de diferenças, de singularidades. E é justamente porque se reconhece como diferença, senão não haveria o novo, que essas singularidades escapam à hipótese de uma pluralidade de imanências isoladas e sem comunicação, e que necessitariam de um solo metafísico para garantir suas relações. Daí que apareça como inevitável para um mundo sustentado pela liberdade a constante reordenação pelos novos empreendimentos,

PRATES, Marcelo. Liberdade, criação e finitude em Sartre: da qualidade singular à generosidade. Griot : Revista de Filosofia, Amargosa - BA, v.19, n.2, p.1-21, junho, 2019. 
seja pelo remanejamento das formas (SARTRE, 1983, p. 551), seja pela reorganização do campo prático, como "remanejamento dos dados anteriores" (SARTRE, 2002a, p. 293) possibilitado pela inércia ${ }^{2}$, como potência própria de instauração de um "novo regime" (Ibid.) pela condição de que "somente a matéria prepara as significações" (Idem, p. 288).

Sartre pensa que tal cristalização das significações na matéria é possibilitada pelo Ser (Idem, p. 292) e não pelo entendimento, ou por uma espécie de memória social, como colocava em $O$ ser e o nada onde delegava ao Outro a condição de salvaguardar na memória a preservação do campo social pertencente a um indivíduo doravante finado. Isso dá uma condição material à criação. Na Crítica, mesmo sem tematizar de forma ontológica, Sartre assume esse revés da criação onde pelo projeto o acontecimento se torna Ser: "ao perder suas propriedades humanas, os projetos dos homens gravam-se no Ser, sua translucidez transforma-se em opacidade, sua tenuidade em espessura, sua ligeireza volátil em permanência; eles tornam-se Ser ao perder seu caráter de acontecimento vivido" (Idem, p. 288). Nesse sentido, o acontecimento como vivência (tomado como fenômeno) é o que possibilita as significações objetivas. Terminadas, repousam na inércia, e só podem ser removidas por um novo empreendimento, uma nova negação, ainda que sejam condição de preparação e pré-disposição da ação ${ }^{3}$. A ação enquanto criação deve fazer o reverso do que a matéria incita ou, como coloca Sartre, "enfraquecer o domínio da materialidade, substituindo a opacidade pela tenuidade, a lentidão pela ligeireza, isto é, criar uma matéria imaterial" (Idem, p. 293). Isso significa que toda criação e transformação é uma retomada do movimento como ação, ação que compreende a negação como momento, mas que é totalização, pois forma um mundo, e cuja totalidade deve se refletir numa nova forma. A dialética é, então, "único método concebido para explicitar a liberdade, para a tornar inteligível e para lhe conservar ao mesmo tempo o seu caráter de criação" (Idem, p. 482).

Assim, a inteligibilidade dialética baseia-se na inteligibilidade de toda determinação nova de uma totalidade prática, enquanto essa determinação nada mais é do que a manutenção e superação totalizadora de todas as determinações anteriores, enquanto essa superação e manutenção são iluminadas por uma totalidade a realizar (Idem, p. 177).

Ainda que o para-si seja uma totalidade destotalizada, seu refluxo no mundo, pela característica da matéria, só pode ser o de determinação do mundo enquanto

\footnotetext{
2 Sobre o papel da inércia é significativa a consideração de Boëchat (2011, p. 75). "A abordagem conferida por Sartre à questão da inércia nos deixa entrever o teor conceitual do materialismo do qual deriva esta última obra. De fato, a noção de matéria não é designada aí como um substrato ontológico ou uma positividade oposta à práxis; ao contrário, como já vimos, é pela unificação do inerte no exterior e pela introdução da inércia no seio da práxis que temos a produção da necessidade no seio das relações humanas".

3 No fundo, é na matéria que se assegura a profundidade da História. Assim, não haveria cultura e História sem a relação dialética do homem singular e da matéria singularizada em seu empreendimento: “Assim, pelas contradições que traz em seu bojo, a matéria trabalhada torna-se para e pelos homens o motor fundamental da História: nela, as ações de todos unem-se e adquirem sentido, isto é, constituem para todos a unidade de um futuro comum; mas, ao mesmo tempo, ela escapa a todos e rompe o ciclo da repetição porque esse futuro - sempre projetado no âmbito da escassez - é inumano; sua finalidade, no inerte meio da dispersão, transforma-se em contrafinalidade ou produz, permanecendo ela mesma, uma contrafinalidade para todos ou para alguns. Portanto, cria por si mesma e como resumo sintético de todas as ações (isto é, de todas as invenções, de todas as criações etc.) a necessidade da mudança" (SARTRE, 2002a, p. 293).
}

PRATES, Marcelo. Liberdade, criação e finitude em Sartre: da qualidade singular à generosidade. Griot : Revista de Filosofia, Amargosa-BA, v.19, n.2, p.1-21, junho, 2019. 
suspenso na liberdade. Por isso que o ciclo de alienação trazia sempre a recaída num mundo alienado depois de superada pela liberdade, mas sem extinguir por completo essa liberdade. Mas, como demonstramos, é justamente nessa diferença que encontramos a pessoa na sua singularidade. Por certo, não há necessidade metafísica do novo (SARTRE, 1983, p. 527), ela, em sua finitude e contingência, é um capricho, mas um capricho que é a própria liberdade (SARTRE, 2002b, p. 229), esta mesma para a qual estamos condenados. Entre a necessidade de se libertar e a necessidade da liberdade, a criação aparece como "sublevação e negação do que é" (SARTRE, 1983 , p. 527) no bojo da personalidade porque implica não o ser contingente, mas, na dialética, toda a História e o indivíduo que a vive, pois ela é "ruptura brutal da repetição cíclica, isto é, como transcendência e espiral (SARTRE, 1985, p. 345). Ademais, é

\begin{abstract}
Porque o relacionamento se verifica no plano da finitude radical, [que] pode-se falar em encarnação histórica. A história não poderia repousar no não-criativo, na eterna repetição de um mesmo objeto, e recusado deve ser também o ponto de vista oposto, que faria da história um projeto transparente para o sujeito. A encarnação como que se espraia num claroescuro, vive de um novo inesgotável e irrepetível, de um novo que se renova por sua própria força (BORNHEIM, 1983, p. 231).
\end{abstract}

Para que a História se consolide enquanto tal a forma do objeto deve ultrapassar a sua objetividade atual e exigir todo vínculo temporal, sua dimensão passada e sua possibilidade futura. É, assim, a sua condição de uso ou, nos termos ontológicos de $O$ ser e o nada, de apropriação. Ali Sartre associa o ato de criar ao ato de ter (SARTRE, 2007, p. 636), pois ter um objeto é justamente manejá-lo e inseri-lo no mundo, mas como meu arredor, de tal modo que nessa trama o objeto é meu porque ele "é este uso e não existe a não ser por isso" (Ibid.). Assim, usar um objeto significa mudá-lo, pois é sempre sendo meu, portanto, um modo singular em que o objeto é tomado, que se segue a apropriação. Deste modo, toda apropriação tem que seguir a lógica da singularidade, tal como Sartre exemplifica com o deslizar da bicicleta que é criada e se torna minha pelo desgaste que minha ação provoca nela, fazendo do objeto seu por seu simples uso, cujo "o desgaste do meu é o reverso de minha vida" (Idem, p. 640), vida para a qual todo o seu engajamento e empreendimento é o modo de realizar tal posse (Idem, p. 639). Com isso, toda relação, por ser singular, implica também criação de mundo, pois o mundo é alicerçado nessa singularidade que é a própria liberdade, não apenas por seu irromper enquanto negatividade, mas pela novidade irredutível ou singularidade com a qual explode e forma o mundo ${ }^{4}$.

Por conta disso, a realização na sua composição enquanto relação singular cria formas específicas e variantes de uso, cujo desdobramento temporal levarão, então, em algum momento, à alguma modificação mais evidente e que se reproduzirá socialmente na matéria. Aqui, a ação e a apropriação tomadas de acordo com o gosto

\footnotetext{
${ }^{4}$ Vale ressaltar que "A estrutura mesma do projeto mais conservador é criação: pois conservar é prolongar à existência uma instituição ou um objeto sob condições que dificilmente são compatíveis com o projeto, esta instituição ou este objeto; é, portanto, dar um sentido novo à instituição que conservamos, é modificá-la perpetuamente e perpetuamente reinventá-la, para a adaptar ao curso do mundo, lhe inventar justificações sempre novas contra ataques sempre novos, etc." (SARTRE, 1983, p. 530).
}

PRATES, Marcelo. Liberdade, criação e finitude em Sartre: da qualidade singular à generosidade. Griot : Revista de Filosofia, Amargosa - BA, v.19, n.2, p.1-21, junho, 2019. 
subjetivo envolvem o objeto segundo a qualidade singular do sujeito, de modo a configurar todos os seus arredores. Em seu próprio ato de fumar Sartre mostra como essa qualidade expressa não somente o todo do indivíduo, mas como é também uma forma singular de vivência. Quando relata seu ato de fumar, seu "ser-suscetível-deser-encontrado-por-mim-fumando", mostra como foi preciso para parar de fumar descristalizar esse empreendimento que já havia se "difundido universalmente sobre todas as coisas. Parecia-me que tal qualidade seria por mim exterminada e que, no meio deste empobrecimento universal, valia um pouco menos a pena viver" (Idem, p. 642). O modo como Sartre descreve revela bem essa condição que a qualidade representa como novo ou sua quebra, enquanto são uma reorganização de mundo:

\begin{abstract}
Para manter minha decisão tive de realizar uma espécie de descristalização, ou seja, sem exatamente me dar conta disso, reduzi o tabaco a não ser senão si mesmo: uma erva que se queima, suprimi seus vínculos simbólicos com o mundo; persuadi-me de que nada perderia da peça de teatro, da paisagem, do livro que lia, se os considerasse sem meu cachimbo; ou seja, voltei-me para outros modos de posse desses objetos que não fosse o dessa cerimônia sacrificatória (Idem, p. 643).
\end{abstract}

Há nesse processo de mudança toda uma condensação de uma nova forma, de um mundo que se modula sem essa sobreposição da fumaça, sem o refúgio do trago, sem que sua posse simbolize a posse total do mundo todo a preencher o vazio que engendra a ação e desenha o mundo por ela. Isso certamente faz de todo ato uma espécie de cerimônia, de rito de passagem, mas sem de modo algum, e Sartre sempre teve muito cuidado com isso, de fazer de tal ato uma concepção, ainda que implique sempre uma universalização em cada escolha, dado que é para o mundo que também se cria. Não é uma concepção porque alude a "escolha da situação concreta em sua incomparável singularidade" (Idem, p. 644), o que sugere que a universalização se expressa no singular e tão somente isso. Qualquer concepção se torna vazia porque a estrutura não sobrepõe o tempo e a profundidade da ação em sua criação e novidade A consistência desse empreendimento singular é tomada como gosto e coloração do indivíduo (SARTRE, 2002a, p. 86) vivido enquanto seu projeto singular de uma totalidade concreta, embora seja este também sempre aberto. Concreta e aberta, essa vivência e o novo que a engendra exige a sua singularidade que se expressa nesse gosto como modo de ser, pois "o nada mesmo que sou é individual e concreto, sendo esta nadificação e não outra" (SARTRE, 2007, p. 645). Portanto, não é ao universal que o para-si se dirige, "mas sim rumo a um novo "estado" concreto do mesmo mundo" (Idem, p. 644) como relação própria do singular com o universal. Trata-se, da diferença no mesmo, da transcendência na imanência, da variação que implica essa multiplicidade de temporalizações numa variante que imprime todo um modo de ser de uma época, bem como seus respectivos desvios pelas personalidades desviantes por seus ritmos dispersos. Mas essa imanência não é um Ser enquanto espírito ou natureza, é a própria finitude enraizada na História.

Por isso, essas personalidades, ainda que não sejam objeto de memória social como a lembrança de um indivíduo específico, são traduzidas como realidades sociais na medida em que são a condição de consolidação e transformação da cultura. Sartre associa esse empreendimento ao próprio fator do humano, fazendo do homem o próprio apanágio do ser. Porque, como expressão do universal, certamente há uma 
forma geral que condiz sobretudo ao mundo comum, mas o que se cria, em última instância, não são seres, por mais que o objeto denote uma singularidade material, nem formas universais, por mais que se abstraia uma forma ou padrão objetivo ou um saber, mas sim este como sentido ou maneira de ser, como o quer no Cahiers, ou fato social, como o quer na Crítica $^{5}$, pois o "conjunto ser-nadificação pode produzir um sentido de $\operatorname{ser}^{6}$ ou compreensão de ser mas não um ser" (SARTRE, 1983, p. 162). Assim, mesmo a mudança social, material, fica às expensas da liberdade, liberdade que não é senão, enquanto maneira de ser, a finitude como o próprio ser. Nesse caso, se o ser é criação, para além da hipótese do em-si-para-si e da impossibilidade do fundamento e da metafísica, é porque todo esse processo implica a finitude: "O ato mesmo de liberdade é assunção e criação da finitude. Se eu me faço, eu me faço finito e, por isso, minha vida é única" (SARTRE, 2007, p. 591)

Assim, frente ao pulular da finitude como mundo, tudo se passa como se todo empreendimento humano se consolidasse como totalidade da cultura, o Espírito objetivo, que passa a englobar "o conjunto de condições sociais, culturais, ideológicas sem as quais o indivíduo perderia as suas bases, o que autorizaria até a asseverar que ele, destituído daquelas condições, stricto sensu não existiria" (BORNHEIM, 1998, p. 21). Aqui nos deparamos novamente com a hipótese do Espírito, que faria do indivíduo um momento de algo maior pela brevidade (SARTRE, 2002a, p. 170) com que sua vida tem ante tal condição histórica e cultural, não possibilitando apenas por ela uma total apreensão da totalização diacrônica e isso não só pelo seu limite temporal, mas também pelo limite que a reflexão lhe impõe ${ }^{7}$. Daí que ela implique esses símbolos universais pela condição do passado totalizado que se faz como cultura.

Sendo assim, encontro-me dialeticamente condicionado pelo passado
totalizado e totalizante da aventura humana: como homem de cultura
(expressão que designa todo homem, seja qual for a sua cultura, inclusive
um iletrado), eu me totalizo a partir de uma história milenar e, na medida
de minha cultura, eu totalizo essa experiência. Isso significa que a minha
própria vida é milenar8, uma vez que os esquemas que me permitem
compreender, modificar e totalizar minhas empresas práticas (e o conjunto

\footnotetext{
${ }^{5}$ A analogia aqui se torna possível porque a partir da Crítica o sentido deixa de ter uma conotação metafísica. Ontologicamente ele aparece como uma maneira de ser, dado que o ser é finitude, e esta é criação de si. Ademais, enquanto enraizado facticamente na História, o sentido, tomado "como orientação da espiral temporal é, ele mesmo, uma significação prática e só se pode compreendê-lo na e pela temporalização" (SARTRE, 1985, p. 305). 6 Também com a proto-história do indivíduo ocorre uma analogia entre o orgânico e o sentido: "na infância o orgânico e o intencional se confundem; assim o sentido é matéria e a matéria, sentido" (SARTRE, 2013, p. 53).

${ }^{7}$ Complementando: "Sartre observa que a dificuldade em determinar com precisão uma verdade histórica reside no fato de que 'o homem faz a História e a faz conhecendo-a' (1989, p. 116), o que significa que a proximidade de sua consciência espontânea e de sua consciência reflexiva não deixa espaço para o conhecimento da objetividade do sujeito que age historializando-se; a objetividade permanece ignorada nesse processo. Essa objetividade só se faz conhecida no futuro, pelas gerações futuras que o colocarão no interior de um quadro no qual ele aparece como um elemento constitutivo de uma totalidade determinada" (BOËCHAT, 2011, p. 306).

${ }^{8}$ Sujeito milenar porque é condicionado por toda História, no sentido de que faz parte dela, porque este mundo aqui exige esta História para ser considerado enquanto tal. Não se trata assim, de apreender o todo, impossível para um ser finito, mas assumir esse todo como condição atual do mundo. Aqui o indivíduo e sua finitude transcendem sua perspectiva rumo à universalização da cultura: "o vínculo totalizante ao passado que constitui o indivíduo pode servir de símbolo a uma totalização de indivíduos" (SARTRE, 2002a, p. 170). Isso implica que todo acontecimento e vida do indivíduo é um acontecimento cultural porque há um certo condicionamento do passado totalizado onde todos os homens estão sujeitos.
}

PRATES, Marcelo. Liberdade, criação e finitude em Sartre: da qualidade singular à generosidade. Griot : Revista de Filosofia, Amargosa - BA, v.19, n.2, p.1-21, junho, 2019. 
de determinações que as acompanham) passam para o atual (presentes por sua eficácia e passados por sua história devinda). Nesse sentido, a evolução diacrônica é atual (enquanto passada - e, veremos isso mais tarde, enquanto futura) na totalização sincrônica; os vínculos entre ambas são de interioridade e, na medida em que a experiência crítica é possível, a profundidade temporal da aventura totalizante revela-se desde o momento em que interpreto reflexivamente as operações de minha vida singular. Aqui, com toda certeza, o indivíduo não é senão o ponto de partida metodológico, e sua curta vida dilui-se no conjunto humano e pluridimensional que temporaliza sua totalização e totaliza sua temporalidade (Idem, p. 171).

Essa diluição do indivíduo por sua brevidade no conjunto total não destitui o fato de que "a totalização é sempre a que um homem faz e ele totaliza o passado até este dia com todos os homens presentes" (SARTRE, 1990, p. 115). A criação, embora irrompida na nadificação, não é sem história. Imerso neste mundo, concreto e real (esse é o ser-em-si enquanto facticidade), a singularidade do indivíduo traz na pluralidade do mundo a singularidade histórica como aprofundamento histórico e real e sua consolidação; onde a criação é também totalização diacrônica e traz, portanto, no ato mesmo de criar, todo o peso da História ao presente e faz a totalidade sincrônica finita não por seu horizonte material inerte, mas pela totalidade diacrônica enquanto totalização histórica por onde meu ato irrompe, arrasta e transforma o meio material sincrônico. Aqui a História exclui a repetição (SARTRE, 1985, p. 28), mas não a multiplicidade, pois um dos elementos rejeitados por Sartre do marxismo (lembrando que faz críticas, mas não abandona o marxismo, pelo contrário, a considera como filosofia insuperável de sua época), é que, de fato, o que existe, são "vários proletariados" (SARTRE, 2002a, p. 76). E mesmo Sartre sendo um visionário que denota um único sentido à História, qual seja, a liberdade, pelo fato de que todo empreendimento humano e cultural conduz unicamente à liberdade, na medida em que esta só pode se manifestar singularmente, ele assume a "pluralidade dos sentidos da História" (Ibid.). Pois, no limite, sendo finita, aludindo a um mundo tecido por uma pluralidade de singularidades, mas também enraizada historicamente, a liberdade não pode ter apenas um sentido, pelo contrário, ela é a condição da pluralidade de sentidos e só pode ser definida por estas existências concretas em sua abertura e finitude.

Tal polivalência é que certifica o mundo em um horizonte infinito (SARTRE, 1990, p. 111), mas que não deixa de ser imanente ainda ao para-si individual, para o qual também é instituído segundo um transcender sem limites, pois sua única limitação real seria sua condição de aniquilamento; daí a radicalidade da doutrina para a qual ou o homem é livre ou não é, sem mais ou menos. Isso porque dentre todas as camadas desse mundo polivalente a liberdade permanece irredutível, embora possa ser alienada ou dissimulada, mas não aniquilada ou expurgada do ser do homem. Entre o mundo como totalidade e os istos como elementos dessa totalidade, há uma variação diacrônica que nas camadas culturais implica desde uma forma mais geral às mais singulares e que são articuladas de acordo com a singularidade", pois "minha escolha, como interiorização da minha finitude, é

${ }^{9}$ Grespan (2006, p. 162 e 163) explana perfeitamente essa relação das significações perante a polivalência da História: “Não haveria uma única significação nos eventos históricos, e sim uma 'multiplicidade', isso é claro. Só

PRATES, Marcelo. Liberdade, criação e finitude em Sartre: da qualidade singular à generosidade. Griot : Revista de Filosofia, Amargosa - BA, v.19, n.2, p.1-21, junho, 2019. 
escolha de um fim finito (Ibid.). Por esta condição essa polivalência está compreendida dentro desse horizonte infinito, mas que se finitiza por minha perspectiva. Toda criação é finita dentro de um horizonte finito (nossa época), mas cuja condição original é infinita: não há limites para a liberdade, embora ela só possa surgir dentro de um limite estabelecido pela necessidade que a criação tem de circunscrever o criado numa situação concreta, para a qual ela singulariza a situação e se singulariza nela. Daí que a maior parte das consequências escapem ao para-si enquanto relação e situação, pois essa ignorância é devido à condição de finitude (Ibid.). Novamente nos deparamos aqui a um infinito, mas não se trata mais da infinitude do fundamento, mas do horizonte limite como liberdade a determinar a finitude no seu ser finito enquanto qualidade singular e concreta como seu máximo de ser (SARTRE, 1983, p. 529). Por isso, sendo a liberdade escolha finita, ela é eleição da finitude sobre um horizonte infinito:

\begin{abstract}
A escolha é interiorização da finitude; a assunção das consequências da escolha (assunção feita na ignorância e no futuro) é interiorização do infinito. Não significa de forma alguma que a ação não deva ser decisão de finitude: só me interesso por um número finito de consequências (ajo na perspectiva desta geração e da seguinte), mas esta decisão mesma aplica um fundo de infinitude [...] (SARTRE, 1990, p. 112).
\end{abstract}

Ora, isso levaria um empreendimento ao infinito não só pela análise biográfica, mas em qualquer análise devido as mutações sincrônicas e a constante variação diacrônica na profundidade temporal que deixam sempre um inacabamento no objeto, já que cada nova combinação pode mudar toda configuração do campo do sujeito, isto é, de sua situação, de modo que determinar essa coloração do projeto implicaria todas essas condições materiais e de "que cada uma dessas determinações forneceria sua própria riqueza, conteria as outras em si" (SARTRE, 2002a, p. 89, negrito meu). Por isso que a singularidade deve ser compreendida como relação e explicitada por uma psicanálise existencial que tomará o indivíduo em todo seu projeto de ser. Em contrapartida, tal infinitude do mundo pela sua pluralidade implica que as significações enquanto universais e calcadas na inércia da matéria sejam objetos sintéticos, mas também "pluridimensionais, indissolúveis, que ocupam lugares singulares em um espaço-tempo com múltiplas dimensões" (Idem, p. 88). Nesse duplo aspecto, na sua relação dialética, Sartre reconhece que o "erro é reduzir a significação vivida ao enunciado simples e linear que lhe é dada pela linguagem (Ibid.), seja pelo vazio que o conceito denota na sua generalidade, seja pela linearidade ou narrativa que se queira dar tanto à vida quanto ao mundo. Por isso que, no fundo, a determinação da finitude não exige uma construção narrativa e

que a referência a uma 'hierarquia' pode nos induzir ao erro de voltar aos esquemas dedutivos. Ao contrário disso, para Sartre ela não autoriza a reduzir as 'significações' umas às outras, como fazem os marxistas: como a 'significação mais geral serve de quadro para a mais concreta, (...) é impossível deduzi-la ou dissolvê-la' (SARTRE, 1986, p.95); a relação entre as significações nos diferentes 'níveis' de generalidade, então, é que as ‘mais gerais' compõem apenas um ‘quadro' mais amplo, e não que precedam logicamente as 'mais concretas'. Por isso, 'é impossível separar estas (...) significações ou reduzi-las uma a outra: elas são faces inseparáveis de um mesmo objeto' (SARTRE, 1986, p.101). Em primeiro lugar, a impossibilidade de 'reduzir' umas às outras indica que elas 'são irredutíveis", no sentido mesmo daquela 'irredutibilidade de um certo real ao pensamento' mencionada antes como característica da crítica de Kierkegaard a Hegel: a significação mais concreta apresenta sempre um resíduo inapreensível pela 'significação mais geral'."

PRATES, Marcelo. Liberdade, criação e finitude em Sartre: da qualidade singular à generosidade. Griot : Revista de Filosofia, Amargosa - BA, v.19, n.2, p.1-21, junho, 2019. 
linear, mas simplesmente a determinação da qualidade fundamental tomando como fio condutor a vida singular do indivíduo porque é ela, sua composição, esta qualidade. Eis a inteligibilidade da criação e do ser em sua finitude. Eis o ser criado em sua finitude e história, que não é senão a relação dialética entre o universal e o singular na totalização diacrônica que o empreendimento mesmo exige.

Ante isso, fica mais fácil compreender porque a criação aponta a uma qualidade singular vivida e exteriorizada como forma da criação de si. Primeiro porque é relação e ação, a qual é possibilitada pela negatividade do para-si, mas que, sendo relação singular, elas não são distintas, sendo, assim, a forma mesma dessa negatividade, impossibilitando ela de ser tomada como uma substância ou como um nada genérico; segundo, porque alude a uma variação que só poderia ser enquadrada numa forma de substância de maneira abstrata e forçada ou inexplicável por um nada genérico, para a qual já perderíamos sua dimensão própria, isto é, singular e finita, sendo estas, então, as únicas condições de engendrar o novo. Aqui, mais que uma substância, é o tempo concreto de uma vida que é sua medida, cuja finitude alude a seu ser. Esse tempo singular subsume essa variação e abertura enquanto unificação e modo de vida. Essa composição pela vida imprime aquilo que Sartre chama de coloração enquanto totalidade vivida e singular, cuja ação sobre o mundo na sua organização faz com que este sofra uma total mudança mesmo que "por uma simples translação na medida em que o mundo é humano (SARTRE, 1983, p. 529). Essa translação dos objetos revela neles uma singularidade e profundidade própria de modo tal que "em um mundo provido de significações e onde cada objeto é o que é em relação ao todo, a translação seja alteração qualitativa" (Ibid.).

Sendo relação ${ }^{10}$, o fenômeno ou para-si denota uma transformação mútua com o mundo, donde se segue a alteração qualitativa no transcendente enquanto a criação apela ao fora, à exterioridade. Ademais, "no espaço hodológico que é o nosso espaço, quer nós queiramos ou não, o lugar de um objeto é uma potencialidade: por seu lugar ele beneficia a força dos polos do espaço hodológico" (Ibid.), cuja condição não anula a autonomia relativa dos setores mediados devido a sua "irredutibilidade prática", isto é, "a impossibilidade de os dissolver no monismo da homogeneidade" (SARTRE, 1985, p. 227), de modo a alterar a significação dos objetos que o cercam e o indivíduo por ele tematizado, uma vez que "a singularidade volta da coisa para o homem"(SARTRE, 2014, p. 1887). É, assim, o movimento da cultura retido na matéria e animado pelas subjetividades que o vivem a se impor na criação singular como contrafinalidade. Ao invés de impedir a criação, justamente ele a radicaliza, pois a resistência vencida ratifica a novidade da criação. Portanto, na relação o mundo adquire sua qualidade de mundo, qualidade que não vem da substância material, mas da coloração das singularidades que lhes recai e que são seladas pela inércia da matéria e reavivada pelos outros, dando, assim, um movimento pluridimensional à mesma História.

Aqui a qualidade se sobrepõe à alienação porque se trata do resultado singular e não a simples alternância de estados desse binômio de maneira linear, o

10 A percepção, aqui, mesmo que singular e prostrada na intencionalidade da consciência, isto é, como negatividade, não é uma estrutura pura para a qual, depois, o mundo viria a ser apreendido. Ela assume-se enquanto tal por seu enraizamento fáctico, condição de sua finitude. Assim, a "qualidade efetiva de minha percepção depende, ao mesmo tempo, de minha atitude social e política e dos acontecimentos contemporâneos" (SARTRE, 2002a, p. 215, negrito meu).

PRATES, Marcelo. Liberdade, criação e finitude em Sartre: da qualidade singular à generosidade. Griot : Revista de Filosofia, Amargosa - BA, v.19, n.2, p.1-21, junho, 2019. 
que impediria a existência como criação, e a denotaria apenas como um atributo possível ao invés de uma qualidade fundamental. Como essa coloração varia pelos objetos e acontecimentos que se inserem na trama singular, a alienação também se refaz com esta coloração, aliás, é na alienação e na superação singular dela que o objeto se refaz, se transformando em novo. Nesse caso, a criação é também uma condição e sua efetivação é uma superação da alienação. E sendo cada objeto uma singularidade e estando o homem inserido numa trama de múltiplos objetos e sentidos (cuja totalização é seu projeto e esse horizonte a situação), a composição dessa coloração é singularização tanto da subjetividade quando do objeto que ela envolve, dando à época histórica seu gosto próprio. Daí a necessidade do método heurístico e do empreendimento biográfico em busca não mais da liberdade e sua queda na alienação, mas na eleição do indivíduo segundo seu projeto de ser enquanto criação da sua singularidade: "Assim, o retorno a biografia mostra-nos os hiatos, as fissuras e os acidentes ao mesmo tempo que confirmam a hipótese (do projeto original), revelando a curva da vida e sua continuidade" (SARTRE, 2002a, p. 113). Portanto, não haveria uma linearidade de estados alienados cuja ruptura ou diferença se daria unicamente pelo intervalo de uma práxis. A qualidade como singularização não é nem somente interior ou exterior, mas a relação destes termos enquanto processo temporal, enquanto nosso sentimento de época e a maneira como nos sentimos e nos fazemos existir. Assim, não é do Ser enquanto projeto de fundamentação que se parte a criação (como se fosse sua possível realização), mas da própria singularidade do projeto existencial (e, nesse caso, o ser é finitude, abertura e processo de finição, cuja qualidade ou fenômeno enquanto seu sentido possível é a singularização), pois, no limite, é só à singularidade que essa criação interessa. $\mathrm{O}$ mundo, por ser fenômeno, é uma aventura humana na contingência do Ser, sua dor perdida na tentativa de se fundamentar: a crise do fundamento faz da finitude o "fundamento" não-metafísico do real, e por isso denota a mesma como liberdade, cuja radicalidade enquanto sentido do ser exige que na criação de si e do mundo essa liberdade apareça como singularidade.

A interiorização como processo de criação de si faz com que a consciência apreenda as modificações do exterior "na unidade das formas" (SARTRE, 1983, p. 551). Se a nadificação se confunde com formação e personalização, a dialética implica essa unidade sempre como uma configuração da situação pelo indivíduo, sendo, então, a chave própria de compreensão do simbolismo existencial das coisas (SARTRE, 2007, p. 649). Daí que tenhamos sempre uma irredutibilidade e profundidade de cada isto singular e que, por isso mesmo, por sua qualidade remeter ao seu quid, à todo o seu ser, (Ibid.), o conjunto formado pela situação alude, na medida que cada ser tem seu quid diferente, a seu desvelamento como forma diferente e diferenciadora (SARTRE, 1983, p. 551) ou uma totalidade nova e reordenada; tangenciado, em contrapartida, uma nova ressignificação a um ou vários objetos desse campo como reflexo da personalização. Só nesse horizonte total e novo a totalização se mostra em seu vigor. Em suma, a qualidade fundamental é uma forma singular fundamental com que imprimo, no movimento dialético, toda uma maneira singular e nova de viver no mundo histórico, por minha própria vida e liberdade. 
Na Crítica Sartre enfatiza toda a densidade da matéria na constituição da História na medida em que as coisas são forças. Mas não retoma ali seu papel de formação na constituição passiva dos primeiros anos, mesmo enfatizando todo o papel da infância no indivíduo. Isso ele o fará, sobretudo, em $O$ idiota da família, mostrando que essa constituição é composição da liberdade na facticidade. Por outro lado, em $O$ ser e o nada, embora ele não traga ali uma tipologia das formas de vida ele não deixa de afirmar como essas formas, em sua condição mais simples, são constituintes da subjetividade. Como nessa obra não é pensada ainda a condição constituinte da infância, a qualidade material aparece ali mais como um caso particular e possível (por uma psicanálise das coisas), mas não ainda privilegiado dentro do estudo biográfico. Assim sendo, a ênfase na Crítica sobre a matéria e, sobretudo, em $O$ idiota da constituição passiva, apontam um privilégio da qualidade material na análise da infância, uma vez que nela o significante se confunde com o significado. Isso possibilita a tomada da singularidade do indivíduo desde seus primeiros anos, de modo a desvelar em seu projeto de ser a qualidade existencial que ele traz ao campo prático.

Em $O$ ser e o nada Sartre associa o ser à qualidade do isto ${ }^{11}$, fazendo da qualidade não uma categoria análoga à substância, mas a expressão do ser em sua finitude. Essa determinação segue a mesma lógica na Crítica de que as coisas são fatos sociais e os fatos sociais são coisas. Mas, enquanto na primeira grande obra a psicanálise existencial e das coisas tem por tarefa extrair o sentido ontológico das qualidades (SARTRE, 2007, p. 645), a partir do mote aqui discutido se torna possível elencá-la a toda configuração inicial que radicará na forma mesma como ato poético e singular da liberdade concreta. Por isso que a determinação da qualidade do isto como a fluidez da água, a densidade da pedra, o sabor do tomate, o rugoso, o liso, sendo "uma certa maneira como o ser se revela e se faz possuir ${ }^{12 " ~(I b i d .) ~ i m p l i c a, ~}$ sobretudo com relação à criança, não apenas uma apreensão do modo de ser, mas o meio ao qual ela interioriza e se faz interiorização, no processo de criação de seu ser. Vale lembrar que na constituição passiva a interiorização é um momento predominante à exteriorização. E se nesse momento o processo de interiorização é predominante, a encarnação, isto é, a maneira como ele assume essas formas, serão constituintes da maneira de ser do indivíduo; por isso, "desde a origem, portanto, o viscoso aparece como um possível eu-mesmo a fundamentar; desde a origem é psiquizado" (Idem, p.652). Mesmo em $O$ ser e o nada Sartre pensa que essa experiência primária cuja forma é um contato absoluto é enriquecedora para a criança e de um

\footnotetext{
11 Aqui vemos bem a associação entre ser e qualidade: "Mas o amarelo do limão não é um modo subjetivo de apreensão do limão: é o limão. Também não é verdade que o objeto x apareça como forma vazia que retém juntas qualidades díspares. De fato, o limão está integralmente estendido através de suas qualidades, e cada uma destas acha-se estendida através de todas as demais. A acidez do limão é amarela, o amarelo do limão é ácido" (EN, p. 222). Também a relação entre gosto e escolha de ser: "Pois não é ao nível do gosto pelo doce ou amargo, etc., que a escolha livre mostra-se irredutível, e sim ao nível da escolha do aspecto do ser que se revela através e pelo doce, amargo, etc." (SARTRE, 2007, p. 646)

12 "Tudo ocorre como se surgíssemos em um universo onde os sentimentos e os atos estivéssemos carregados de uma materialidade, ostentassem uma textura substancial, fossem verdadeiramente delicados, chatos, viscosos, baixos, elevados, etc., e onde as substâncias materiais tivessem originariamente uma significação psíquica que as fizessem repugnantes, horríveis, atraentes, etc. Nenhuma explicação por projeção ou por analogia é admissível neste caso. E, para resumir, é impossível extrair o valor de símbolo psíquico do viscoso partindo da qualidade em bruto do "Isto", bem como é impossível projetar esta significação sobre o isto a partir de um conhecimento das atitudes psíquicas consideradas" (Idem, p. 651 e 652)
}

PRATES, Marcelo. Liberdade, criação e finitude em Sartre: da qualidade singular à generosidade. Griot : Revista de Filosofia, Amargosa - BA, v.19, n.2, p.1-21, junho, 2019. 
enriquecimento moral e psicológico, que se traduzirá na escolha de ser e em toda sua personalidade posterior:

\begin{abstract}
O viscoso se revela de per si como "muito mais que o viscoso"; desde sua aparição, transcende todas as distinções entre o psíquico e o físico, entre o existente em bruto e as significações do mundo: constitui um sentido possível do ser. A primeira experiência que a criança pode fazer do viscoso a enriquece, portanto, psicológica e moralmente: ela não terá a necessidade de esperar a idade adulta para descobrir o gênero de baixeza aglutinante que denominamos figurativamente "viscoso": está aí, junto dela, na própria viscosidade do mel ou da cola. $\mathrm{O}$ que dissemos sobre o viscoso vale para todos os objetos que cercam a criança: a simples revelação de sua matéria amplia o horizonte da criança até os extremos limites do ser e, ao mesmo tempo, dota-a de um conjunto de chaves para decifrar o ser de todos os fatos humanos. Não significa que ela conheça na origem as "feiuras" da vida, os "caracteres, ou, ao contrário, as "belezas" da existência. Simplesmente encontra-se em poder de todos os sentidos de ser dos quais feiúras e belezas, condutas, traços psíquicos, relações sexuais, etc., jamais serão mais do que exemplificações particulares. $\mathrm{O}$ pegajoso, o pastoso, o vaporoso, etc., buracos na areia e na terra, cavernas, a luz, a noite, etc., revelam à criança modos de ser pré-psíquicos e pré-sexuais que ela depois passará a vida explicitando. Não há criança "inocente" (Idem, p. 658, negrito meu).
\end{abstract}

Nesse sentido, a qualidade fundamental do indivíduo é uma singularização de todas as qualidades dos istos interiorizados segundo uma conjuntura histórica e singularizados por um projeto de ser e escolha do indivíduo sobre seu ser. $O$ projeto de ser e escolha de ser não é, assim, uma atitude reflexiva, mas alude à totalidade vivida pelo indivíduo. Eis o sentido da criação enquanto criação da finitude como maneira de ser e sentido do ser. A coloração se faz dessa síntese de qualidades materiais e historicamente determinadas sob a singularização enquanto constituição passiva e personalização do indivíduo. Certamente essa qualidade que traduz uma escolha de ser implica uma complexidade maior na sua constituição, mas que carrega em si estes traços na medida em que são esses primeiros que trouxeram toda uma configuração fáctica inicial para ser ultrapassada pelo projeto de ser. E sendo interiorização e processo, cada vez mais essa qualidade interiorizada assume uma maneira singular de se relacionar a ela e de se expressar no mundo que, solidificado como personalidade, traduz-se como ato poético do sujeito e sua coloração ou qualidade singular, como, por exemplo, o papel das palavras para Sartre na sua infância e no papel que dará à literatura na sua vida adulta, a relação entre liberdade e o papel do escritor, sobretudo sobre a situação do escritor em 1948, etc..

Assim sendo, a totalidade do indivíduo enquanto criação de si deve se apresentar em cada gesto, gosto, pensamento, de modo que cada novo movimento deve traduzir sua escolha e maneira de ser como forma da sua personalidade, sendo, portanto, a conjuntura que se singulariza enquanto modo próprio de como a vivência se faz viver (SARTRE, 2013, p. 394). Daí que as constantes da imaginação poética não sejam explicadas por uma genialidade ou loucura, mas por uma escolha de ser, onde o "geológico" em Rimbaud, a fluidez da água em Poe, a náusea em Roquentin, a passividade em Flaubert, as palavras e a liberdade, e mesmo a fumaça do tabaco que Sartre acusa a si mesmo, expressam um modo singular de possuir o mundo e de 
modificá-lo, enfim, de viver nele e fazê-lo suspenso na liberdade. Nesse sentido, o roubo em Genet não é apenas um ato, mas uma qualidade existencial que traduz todo o seu ser que não é mais um mero roubo ou o roubo, assim como a animalidade para Lautréamont "pressupõe uma decifração do sentido objetivo do animal" (SARTRE, 2007, p. 648), pois ele "coloca" nela "algo distinto e mais rico do que eu coloco" ao mesmo passo que na polarização da estrutura objetiva da animalidade nos informam sobre o próprio Lautréamont, bem como a psicanálise dele pressupõe "uma decifração do sentido objetivo do animal" (Ibid.). Aqui vemos como essa qualidade implica uma diferença que exige que o universal seja tomado somente por sua singularidade, se se quer compreendê-lo em sua concretude:

Compreende-se que, com isso, o sabor recebe uma arquitetura complexa e uma matéria diferenciada; é esta matéria estruturada - que nos apresenta um tipo de ser singular que podemos assimilar ou rejeitar com náuseas, de acordo com nosso projeto original. Portanto, não é em absoluto indiferente gostar de ostras ou moluscos, caracóis ou camarões, por pouco que saímos deslindar a significação existencial desses alimentos. De modo geral, não há paladar ou inclinação irredutível. Todos representam certa escolha apropriadora do ser (Idem, p. 662).

Deste modo, a subjetividade ao implicar a personalidade revela no gosto um modo de ser que é a expressão da totalidade do ser do indivíduo, de modo que esse indivíduo expressa na existência um gosto de ser, uma forma possível pela qual o ser se aventura. Se todo esse projeto pode ser condensado no fato poético, não como chaga maior, mas como melodia construída como totalidade do existente, como modo singular de vida enquanto forma de escapar ao seu destino social, a designação do universal deverá trazer consigo a marca dessa subjetividade. E embora Sartre enfatize algumas personalidades, como a de Flaubert, por exemplo, o faz sempre pensando no Homem como ser que é seu fazer, como condição construída ao qual tudo radica. No fundo, seu humanismo procura salvaguardar a subjetividade como transcendental histórico. Também tenta mostrar que o mundo e a História são humanas pelo fato de que só no humano encontramos esse processo de singularização e exteriorização. Por isso que não se trata nem de um humanismo clássico, mas também nem de um humanismo individualista, mas que se calca no homem concreto segundo seus projetos e modos de vida. A cultura é humana porque só o homem é livre, e livre não só porque nele ocorre uma negatividade, uma fissura no ser, mas porque há a personalização constante, cujo refluxo é a construção histórica da cultura, ao preço de que sua condição seja sua finitude, fazendo da ordem do sentido, no transcorrer de sua vida enquanto facticidade e transcendência, os limites inteligíveis e concretos da finitude.

Ora, essa forma de existência, que expressa e manifesta a finitude e singularidade de uma irredutibilidade que irrompe na contingência por sua criação de si aparece, paradoxalmente, enquanto fenômeno, como doação de ser (mas não do fundamento, melhor seria dizer do ser enquanto qualidade fundamental). "Doar, essa é a verdadeira palavra" (SARTRE, 1983, p. 157), pois "a criação é também processo de doação." (Idem, p. 135). Por um lado, como observamos, ela é dirigida para fora, é uma explosão criadora como mundo, por outro, esse processo de fazer-se existir e fazer existir o mundo também, é "comunicação de ser", pois "só podemos doar o que 
temos" (Idem, p. 157), nesse caso, o que nos fazemos. E dizemos que se apresenta e se comunica ao outro porque o novo não é algo vivido apenas subjetivamente, mas exige, para se dar como diferença, o assentimento do outro ${ }^{13}$ : "A criação implica necessariamente a objetivação e a objetivação só pode ser feita pelo outro; senão o sentido seria, para quem cria, tintura superficial de um mundo irremediavelmente estranho. Criamo-nos a nós mesmos se doando ao outro" (Idem, p. 136). Isso desmistifica toda ideia de solidão ontológica que poderia transparecer ou mesmo de irremediável conflito ontológico nas relações humanas. Essa relação necessária com o outro dá um sentido diferente que o da alienação ou da ideia de que o outro é sempre fator de alienação. Pois essa teia é enriquecimento do mundo, de modo que, por contribuir na sua complexidade, ela se torna fator necessário para aprofundamento do mundo e minha singularização.

Além do mais, Sartre aponta aqui a possibilidade não só da objetivação do mundo na construção da História com o outro, mas a tomada da subjetividade, da singularidade do indivíduo: "Eu dou este mudo a ver, eu o faço existir para ser visto e neste ato eu me perco como uma paixão" (Idem, p. 137). Nesse caso, não se trata apenas de conferir uma objetividade, mas entrar em contato com àquilo que é ao mesmo tempo irredutível e condição dessa irredutibilidade, e aponta, na condição humana, não um humanismo essencialista, mas a construção conjunta da cultura humana: "a generosidade absoluta e sem limites, como paixão propriamente dita e como único meio de ser. Não há outra razão de ser que se doar. E não é apenas a obra que é doação. O personagem (caractère) é doação. O Eu (Moi) é a rubrica unificadora de nossa generosidade" (Idem, p. 137). Esse tipo de conhecimento que é construído e se dá de uma subjetividade para outra, de uma liberdade para outra, Sartre chamará de compreensão. A análise da finitude é a compreensão das liberdades. Ela é, enquanto forma de conhecimento, "simplesmente o movimento dialético que explica o ato pela sua significação terminal a partir de suas condições de partida" (SARTRE, 2002a, p. 115). Nesse sentido, "a compreensão refere-se sempre a um processo, e é a antítese do saber absoluto" (SILVA, 2003, p. 57). Por outro lado, ela apela ao outro e toma o outro em sua doação porque, em sua criação de si, o outro aparece como um convite à compreensão de nós mesmo (SARTRE, 1972, p. 186). Para a compreensão trata-se de assumir que há não uma tomada objetiva e final do outro, mas um recomeço que exige que, pela compreensão, eu recomece o mundo pelo movimento de minha própria temporalização (Ibid.). A compreensão é a tomada do processo por mim mesmo, sem destituir a minha liberdade ou a do outro. É nisso que se dá a generosidade da construção do mundo na existência singular.

Portanto, não é da coisa para a coisa, do conceito para o conceito, mas é do singular para o singular que a criação se efetua. Aqui o universal não é senão o lastro abstrato suplantado por uma matéria que retém, por sua inércia, essa condição de conservação e dá consistência ao mundo fáctico como solo histórico das relações

\footnotetext{
13 A relação entre verdade e assentimento é bem exposta por Boëchat (2011, p. 299): "o processo de verificação de uma verdade não se dá, portanto, unicamente pela ação daquele que a sustenta. É com o outro e através do outro que sua recuperação se complementa. Seu desvelamento implica a relação da consciência com uma multiplicidade de existentes. Assim sendo, por um lado, a recuperação e a transformação de uma verdade devinda em uma verdade deveniente implica simultaneamente o reconhecimento pela consciência do aspecto comunicativo de uma verdade e a implicação do reconhecimento mútuo de uma pluralidade de liberdades. Além disso, essas liberdades, ao mesmo tempo em que se temporalizam, perpetuam também o incessante renascimento da verdade."
}

PRATES, Marcelo. Liberdade, criação e finitude em Sartre: da qualidade singular à generosidade. Griot : Revista de Filosofia, Amargosa - BA, v.19, n.2, p.1-21, junho, 2019. 
humanas, pelas quais e a partir das quais elas se constroem. A teia da História é, deste modo, o reflexo do homem em sua liberdade. A generosidade é a criação conjunta e dinâmica da história e da cultura. "Assim, para terminar, toda criação é uma doação e não poderia existir sem se doar" (SARTRE, 1983, p. 137). É o que experimentamos ao existir como contingência fáctica e irredutível novidade a implodir no mundo com o outro; eis a liberdade e a finitude humana, onde cada tempo, cada conjuntura na sua situação e complexidade, dá o gosto e dá a compreender o que é o homem em sua liberdade, que homem foi criado neste tempo na História e, no limite de sua finitude e tempo, que homem haverá por vir. 


\section{Referências:}

BOËCHAT, Neide Coelho. História e escassez em Jean-Paul Sartre. São Paulo: EDUC: FAPESP, 2011.

BORNHEIM, Gérd Alberto. O Idiota e o Espírito objetivo. Rio de Janeiro: UAPÊ e SEAF, 1998.

BORNHEIM, Gérd Alberto. Dialética: teoria e práxis - ensaio para uma crítica da fundamentação ontológica da Dialética. 2. ed. Porto Alegre: Globo, 1983.

FRAJOLIET, Alain. Ontologie, morale, histoire. Le Portique [En ligne], 16 | 2005, mis en ligne le 15 juin 2008, consulté le 15 septembre 2015 . URL: http://leportique.revues.org/735.

GRESPAN, Jorge. Sartre, Marx e o Marxismo. In: Dois Pontos: Sartre, Curitiba, UFPR, v. 3, n. 2. 2006.

SARTRE, Jean-Paul. Cahiers por une morale. France: Gallimard, 1983.

SARTRE, Jean-Paul. Crítica da razão dialética - Tomo I: Teoria dos conjuntos práticos, precedido por Questão de método. Tradução: Guilherme João de Freitas Teixeira. Rio de Janeiro: DP\&A, 2002a.

SARTRE, Jean-Paul. Critique de la raison dialectique - tome II - l'inteligibilté de la históire. France : Galimard, 1985.

SARTRE, Jean-Paul. L'être et le néant - Essai d'ontologie phénoménologuique. France: Gallimard, 2007.

SARTRE, Jean-Paul. L' Universel Singulier. In: Situations IX. France: Gallimard, 1972.

SARTRE, Jean-Paul. O Idiota da Família - Gustave Flaubert de 1821 a 1857. Vol. 1. Porto Alegre, RS: L\&PM, 2013.

SARTRE, Jean-Paul. O Idiota da Família - Gustave Flaubert de 1821 a 1857. Vol. 2. Porto Alegre, RS: L\&PM, 2014.

SARTRE, Jean-Paul. Saint Genet - ator e mártir. Petrópolis, RJ: Vozes, 2002b.

SARTRE, Jean-Paul. Verdade e existência. Tradução: Marcos Bagno. Rio de Janeiro: Nova Fronteira, 1990.

SILVA, Franklin Leopoldo e. Conhecimento e identidade histórica em Sartre. In: Trans/form/Ação, São Paulo, 26(2): 43-64, 2003.

Autor(a) para correspondência: Marcelo Prates, Universidade Estadual do Centro-Oeste, R. Salvatore Renna, 1606-1730 - Santa Cruz, Guarapuava, 85015-430, Paraná - PR, Brasil. marceloprates1@gmail.com 